\title{
Designing General Anesthetics That Have a Better Safety Profile
}

\author{
Robert B. Raffa, ${ }^{1,2,3}$ Joseph V. Pergolizzi Jr.1,4, Robert Taylor Jr.4 \\ ${ }^{1}$ Neumentum Inc., Palo Alto, CA, USA \\ ${ }^{2}$ College of Pharmacy, University of Arizona, Tucson, AZ, USA \\ ${ }^{3}$ Temple University School of Pharmacy, Philadelphia, PA, USA \\ ${ }^{4}$ NEMA Research Inc., Naples, FL, USA \\ Email: robert.raffa@temple.edu
}

How to cite this paper: Raffa, R.B., Pergolizzi Jr., J.V. and Taylor Jr., R. (2019) Designing General Anesthetics That Have a Better Safety Profile. Pharmacology \& Pharmacy, 10, 407-415.

https://doi.org/10.4236/pp.2019.1010033

Received: August 10, 2019

Accepted: October 8, 2019

Published: October 11, 2019

Copyright (c) 2019 by author(s) and Scientific Research Publishing Inc. This work is licensed under the Creative Commons Attribution International License (CC BY 4.0).

http://creativecommons.org/licenses/by/4.0/

\begin{abstract}
General anesthetics constitute some of the most important and widely-used therapeutic drugs in the pharmacotherapeutic armamentarium. They are routinely used effectively and with adequate precaution-safety throughout the world for a multitude of clinical applications, predominantly as adjunctive agents for surgical procedures. Nevertheless, they have potential adverse effects (such as a drop in blood pressure and the inhibition of steroid production), particularly in vulnerable populations such as the very young and the frail elderly. It would be desirable therefore to have alternative agents that are just as efficacious, but have a better safety profile in a broader spectrum of patients. Toward this end, an anesthetic based on a unique chemical core (viz., an $N$-arylpyrrole derivative) has been reported in preclinical models to produce anesthetic effects without hemodynamic suppression. This lead could pave the way for new general anesthetics that are safer and easier to use.
\end{abstract}

\section{Keywords}

General Anesthetic, Intravenous, Drug Discovery, $\mathrm{GABA}_{\mathrm{A}}$ Receptor, Molecular Modeling

\section{Introduction}

General anesthetics possess characteristics that make them valuable for use during a wide variety of surgical procedures [1] [2] [3]. However, no drug is perfect, and the commonly-used general anesthetics produce adverse effects (AEs) in some patients. The most common of the AEs related to this drug class are he- 
modynamic (a significant drop in blood pressure) or endocrinologic related (inhibition of synthesis of steroids) [4]. These AEs are usually adequately avoided or handled by the anesthesiologist, but vulnerable populations, such as the very young or the frail elderly, are more at-risk [5] [6] [7] [8].

General anesthetics share common biological effects, but consist of a perplexing array of differing chemical structures (Figure 1). The group includes molecules as small as the single atom xenon, and as large as the 56-atom alfaxalone [9] [10] [11]. Such chemical diversity impeded the discovery of a common mechanism of action. Many theories have been proposed [12]. It is now accepted that most of the commonly-used general anesthetics act by an action on a specific sub-region of the large $\gamma$-aminobutyric acid type $A$ receptor $\left(G_{A B A} R\right)$ complex (Figure 2) [13] [14] [15] [16]. They act at these sites as positive allosteric modulators [17] [18] [19]. That is, at therapeutic doses they do not bind to the same site as does GABA, but their binding to a separate site on the complex enhances the action of GABA, namely, increase in $\mathrm{Cl}^{-}$ion influx [19] [20] [21]. This results in an inhibitory effect on neuronal excitability (Figure 3) [22] [23].

The currently-used general anesthetics generally do not have exclusive activity at only $\mathrm{GABA}_{\mathrm{A}}$ receptors. They also have activity at other receptor sites as well [13]. For example, propofol has some activities at subtypes of glutamate, nicotinic acetylcholine, and histamine receptor sites [24] [25] (Table 1). It seems plausible that the non-GABA $A_{A}$ sites contribute to the AEs of the general anesthetics. Therefore, it might be possible to design molecules that interact more selectively with only $\mathrm{GABA}_{\mathrm{A}}$ sites. If so, the safety profile might be improved over currently-used drugs. Cayla et al. (2019) recently reported on the discovery and the properties of a newly developed anesthetic based on a unique chemical core [26].

\section{The Discovery Approach}

\subsection{The $\mathrm{GABA}_{\mathrm{A}} \mathrm{R}$ and General Anesthetic Action}

The $\mathrm{GABA}_{\mathrm{A}}$ receptor is a member of the ligand-gated ion channel (LGIC) Cys-loop class of receptors. Five subunits $\left(\gamma-\alpha-\beta-\alpha\right.$ - $\beta$ linkage) form a central ion $\left(\mathrm{Cl}^{-}\right)$conducting pore. General anesthetics potentiate the action of GABA (transmembrane $\mathrm{Cl}^{-}$influx), resulting in hyperpolarization and inhibitory actions on neurons [27] [28].

General anesthetics are believed to bind to the transmembrane region of the $\mathrm{GABA}_{\mathrm{A}} \mathrm{R}$, and interaction with specific amino acid residues is believed to be<smiles>CCCC(C)C1(CC)C(=O)NC(=S)NC1=O</smiles>

Figure 1. Diverse chemical structures of representative general anesthetics. 

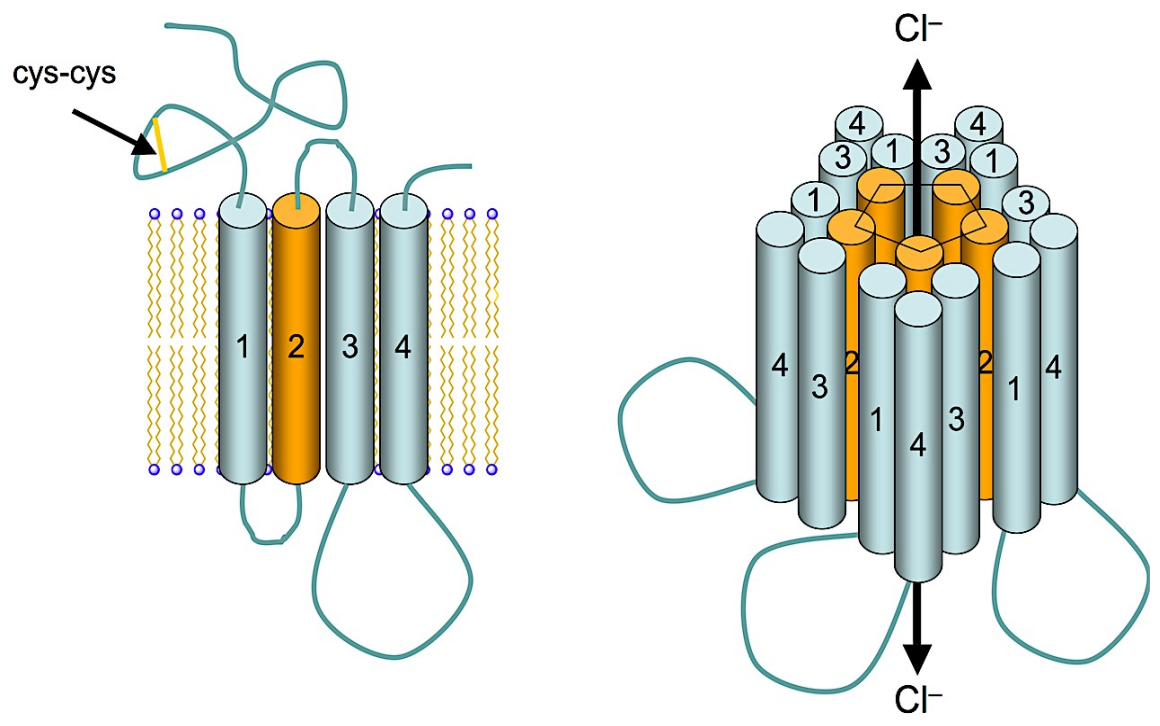

Figure 2. Schematic representation of the heteropentameric $\mathrm{GABA}_{\mathrm{A}}$ receptor complex. From https://upload.wikimedia.org/wikipedia/commons/thumb/0/06/GABAA_receptor_schem atic.png/1280px-GABAA_receptor_schematic.png.

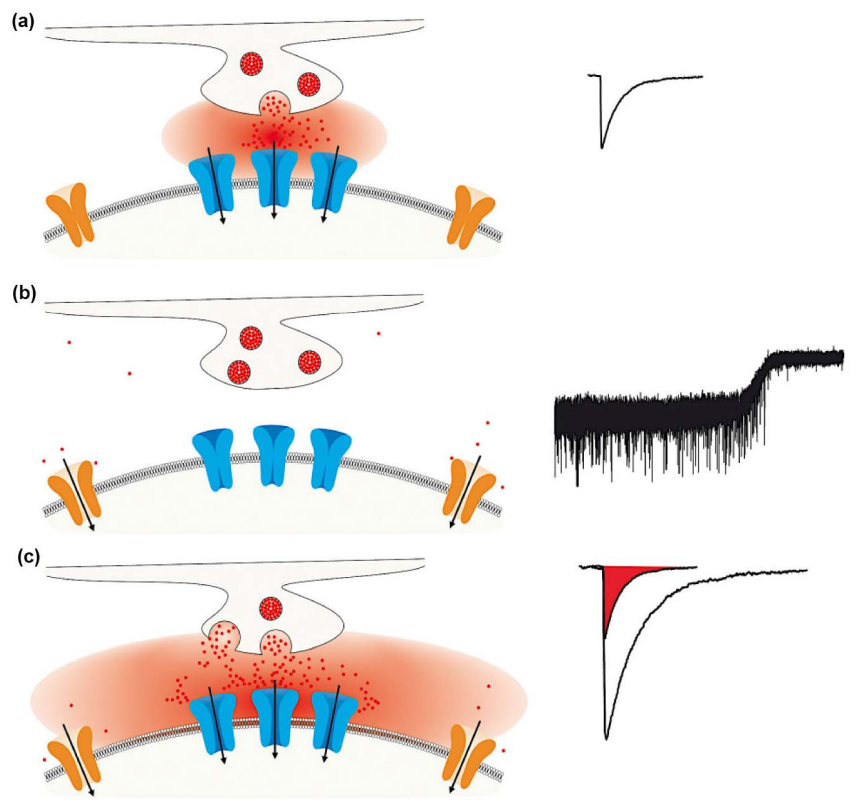

Figure 3. (a) Release of GABA red dots and cloud) from presynaptic vesicles results in inhibitory postsynaptic currents (IPSCs). (b) Extrasynaptic receptors (orange) result in a persistent inhibition. (c) Increased and prolonged IPSC relative to synaptic inhibition. From [22] [23] with permission.

essential for anesthetic action [29] [30]. The binding potentiates the action of the native $\mathrm{GABA}_{\mathrm{A}} \mathrm{R}$ ligand GABA, which converts the LGIC from a more closed to a more open conformation, allowing $\mathrm{Cl}^{-}$ion flux through the central pore formed by the heteropentameric subunits. The $\mathrm{Cl}^{-}$influx results, at the neurophysiological level, in hyperpolarization of the postsynaptic neuron, with subsequent less 
Table 1. Non-selective activity profile of some general anesthetics [24] [25] [32] [33]. Up arrows indicate enhancement, down arrows indicate inhibition. Number of arrows indicates qualiatative magnitude.

\begin{tabular}{|c|c|c|c|c|c|c|}
\hline Anesthetic & $\mathrm{GABA}_{\mathrm{A}}$ & Glycine & AMPA/Kainate & $\begin{array}{c}\text { NMDA } \\
\text { (+Gly) }\end{array}$ & Nicotinic-ACh & $5-\mathrm{HT}_{3}$ \\
\hline Alphaxalone & $\uparrow \uparrow \uparrow \uparrow$ & & & & $\downarrow \downarrow$ & \\
\hline Etomidate & $\uparrow \uparrow \uparrow$ & & & & & \\
\hline Pentobarbital & $\uparrow \uparrow \uparrow$ & & $\downarrow \downarrow$ & $\downarrow$ & $\downarrow \downarrow \downarrow$ & $\downarrow$ \\
\hline Propofol & $\uparrow \uparrow \uparrow$ & $\uparrow$ & & & $\downarrow \downarrow$ & $\downarrow$ \\
\hline
\end{tabular}

likelihood to fire (action potential) in response to excess presynaptic activity. This is mirrored at the organism level in an anesthetic action [20] [31].

\subsection{Computational Chemistry to Model the $\mathrm{GABA}_{\mathrm{A}} \mathrm{R}$}

Isolation and purification of LGIC receptors such as the $\mathrm{GABA}_{\mathrm{A}} \mathrm{R}$ is technically difficult, and there were no high-resolution crystal structures of the open-state of the $\mathrm{GABA}_{\mathrm{A}} \mathrm{R}$, the conformation to which general anesthetics are thought to interact and stabilize [28], so Bertaccini and colleagues used computational chemistry to construct a homology model of the $\mathrm{GABA}_{\mathrm{A}} \mathrm{R}$ [30] [34].

The amino acid sequences for the human $\mathrm{GABA}_{A} \mathrm{R}\left(\mathrm{hGABA_{A }} \mathrm{R}\right)$ were obtained from the National Center for Biotechnology Information (NCBI). Then, in short, homologous template receptors were identified from imported $G_{A B A} R$ subunit sequences based on their sequence similarity. The sequence for each $h G A B A_{A} R$ subunit was then aligned to the corresponding subunit of the template, arranged for modeling, and connected in order to create a 3-dimensional model of a complete heteropentameric $\mathrm{hGABA}_{\mathrm{A}} \mathrm{R}$. The resultant homology model is shown in Figure 4 [34].

\subsection{Modeling the General Anesthetic Binding Pocket}

The energetically minimized, optimized homology model of the $\mathrm{hGABA}_{\mathrm{A}} \mathrm{R}$ (as described above) was used to model the transmembrane intersubunit space that is thought to be the binding site for general anesthetics [30]. Three amino acid residues that were previously shown to be essential for anesthetic activity $\left(\beta_{3}\right.$-N265, $\beta_{3}$-M286, $\alpha_{1}$-L232) were mapped to form a putative anesthetic binding pocket. A molecule of propofol was manually docked in this binding pocket in an orientation to mimic pharmacologic relevance (e.g. minimizing steric hindrance) and an energetically-optimized binding cavity was obtained. A series of propofol derivatives were fit to the model and used to test model reliability by comparing calculated binding affinities with known values.

\section{Identification of Novel Anesthetic Compounds}

Using the above model of the binding pocket for general anesthetics on the human $\mathrm{GABA}_{\mathrm{A}}$ receptor, Cayla et al. (2019) used high-throughput in silico screening 

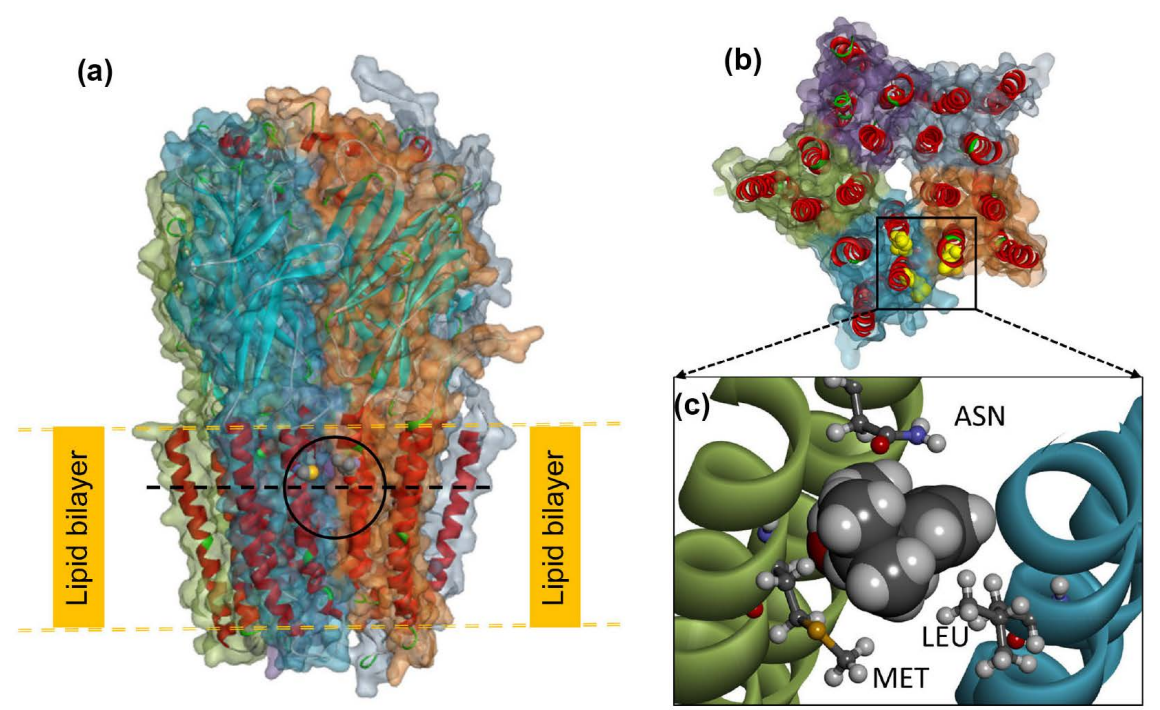

Figure 4. (a) In silico homology model of the human $\mathrm{GABA}_{\mathrm{A}}$ receptor; (b) cross sectional view; and (c) intersubunit binding site of propofol. From [34] with permission.

to identify candidate compounds that exhibited goodness of fit to the modelled binding pocket, and thus were potential mimetics of current general anesthetics with potential anesthetic action of their own [26].

In addition to the hGABA $\mathrm{R}$ docking procedure used to model efficacy, it was desired to also address the $\mathrm{AE}$ issues associated with general anesthetics. Toward this end, previous findings related to the known unwanted interaction of etomidine with the enzyme thought to be related to the AE of adrenal suppression, 11- $\beta$-hydroxylase [35] [36], were incorporated, resulting in a unique molecular core in silico [37] [38] [39] [40]. High-throughput structural screening identified 11 compounds that have 'fits' compatible with the critical binding core. The most potent of the 11 compounds, an $\mathrm{N}$-arylpyrrole derivative (Figure 5), termed "BB", was tested in vitro and in vivo for anesthetic activity and AE potential.

The in vitro testing revealed:

- $\mathrm{BB}$, similar to etomidate, acts specifically through $\mathrm{GABA}_{\mathrm{A}} \mathrm{R}$-slow receptors (propofol has additional effects on $\mathrm{GABA}_{\mathrm{A}} \mathrm{R}$-fast and tonic receptors) [41] [42].

- The effect was fully reversed by the $\mathrm{GABA}_{\mathrm{A}} \mathrm{R}$-selective $\mathrm{Cl}^{-}$ion channel blocker picrotoxin.

- BB slowed decay of electrically-evoked IPSCs (inhibitory postsynaptic currents) in whole-cell voltage-clamp recordings from CA1 pyramidal cells in mice.

- $\mathrm{BB}$ dose-dependently potentiated GABA-induced currents on $\mathrm{GABA}_{\mathrm{A}}$ receptors expressed in Xenopus oocytes.

\subsection{In Vivo Evaluation of Potential Anesthetic Activity}

The potential anesthetic activity of $\mathrm{BB}$ was tested in vivo using the standard methods 


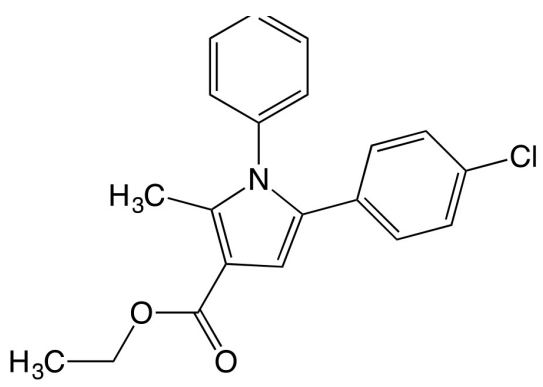

BB

Figure 5. Chemical structure of lead compound "BB" [26].

of measuring the loss-of-righting reflex (LORR) in tadploes and rats [43] [44]. BB produced dose-related LORR in tadpoles, which was reversed when the animals were subsequently placed into a drug-free water bath.

Likewise, intravenous injection of $\mathrm{BB}$ to rats produced a reversible loss of righting-reflex, without signs of abnormal behavior or toxicity.

\subsection{In Vivo Evaluation of Potential AE Activity}

The hemodynamic profile of compound $\mathrm{BB}$ was tested in rats and compared to propofol.The intravenous injection of propofol at a typical anesthetic-induction dose produced a significant decrease in both systolic and diastolic arterial blood pressure. In contrast, at a dose more than 4 -fold that required producing LORR, BB did not alter either systolic or diastolic arterial blood pressure [26].

Etomidate interacts with the heme iron in 11- $\beta$-hydroxylase and, as a result, causes an almost complete suppression of the synthesis of corticosterone [45]. In contrast, in the same procedure, compound BB did not alter baseline of ACTHstimulated corticosterone levels in rats [26].

\section{Conclusion}

Compound BB recently reported by Cayla et al. (2019) might provide the anesthetic efficacy of currently-used general anesthetic drugs, but with a better safety profile. However, even in the absence of future clinical utility, the approach (in silico modeling and compound screening coupled with in vivo efficacy and adverse-effect testing) provides an elegant demonstration of the power of computer-modeling techniques toward drug discovery.

\section{Conflicts of Interest}

The authors declare no conflicts of interest regarding the publication of this paper.

\section{References}

[1] Brown, E.N., Pavone, K.J. and Naranjo, M. (2018) Multimodal General Anesthesia: Theory and Practice. Anesthesia \& Analgesia, 127, 1246-1258. 
https://doi.org/10.1213/ANE.0000000000003668

[2] Goodchild, J.H. and Donaldson, M. (2017) New Sedation and General Anesthesia Guidelines: Why the Changes? The Journal of the American Dental Association, 148, 138-142. https://doi.org/10.1016/j.adaj.2016.12.030

[3] Robinson, D.H. and Toledo, A.H. (2012) Historical Development of Modern Anesthesia. Journal of Investigative Surgery, 25, 141-149. https://doi.org/10.3109/08941939.2012.690328

[4] Berthoud, M.C. and Reilly, C.S. (1992) Adverse Effects of General Anaesthetics. Drug Safety, 7, 434-459. https://doi.org/10.2165/00002018-199207060-00005

[5] De Francisci, G., et al. (2013) Update on Complications in Pediatric Anesthesia. Pediatric Reports, 5, e2. https://doi.org/10.4081/pr.2013.e2

[6] Bartels, D.D., et al. (2018) Estimating Pediatric General Anesthesia Exposure: Quantifying Duration and Risk. Pediatric Anesthesia, 28, 520-527.

https://doi.org/10.1111/pan.13391

[7] Kanonidou, Z. and Karystianou, G. (2007) Anesthesia for the Elderly. Hippokratia, 11, 175-177.

[8] Strom, C., Rasmussen, L.S. and Sieber, F.E. (2014) Should General Anaesthesia Be Avoided in the Elderly? Anaesthesia, 69, 35-44. https://doi.org/10.1111/anae.12493

[9] Lawrence, J.H., Loomis, W.F., Tobias, C.A. and Turpin, F.H. (1946) Preliminary Observations on the Narcotic Effect of Xenon with a Review of Values for Solubilities of Gases in Water and Oils. The Journal of Physiology, 105, 197-204. https://doi.org/10.1113/jphysiol.1946.sp004164

[10] Cullen, S.C. and Gross, E.G. (1951) The Anesthetic Properties of Xenon in Animals and Human Beings, with Additional Observations on Krypton. Science, 113, 580-582. https://doi.org/10.1126/science.113.2942.580

[11] Laubach, G.D., P’An, S.Y. and Rudel, H.W. (1955) Steroid Anesthetic Agent. Science, 122, 78. https://doi.org/10.1126/science.122.3158.78-a

[12] Turin, L., Skoulakis, E.M. and Horsfield, A.P. (2014) Electron Spin Changes during General Anesthesia in Drosophila. Proceedings of the National Academy of Sciences of the United States of America, 111, E3524-E3533. https://doi.org/10.1073/pnas.1404387111

[13] Weir, C.J., Mitchell, S.J. and Lambert, J.J. (2017) Role of GABA Receptor Subtypes in the Behavioural Effects of Intravenous General Anaesthetics. British Journal of Anaesthesia, 119, i167-i175. https://doi.org/10.1093/bja/aex369

[14] Son, Y. (2010) Molecular Mechanisms of General Anesthesia. Korean Journal of Anesthesiology, 59, 3-8. https://doi.org/10.4097/kjae.2010.59.1.3

[15] Franks, N.P. and Lieb, W.R. (1990) Mechanisms of General Anesthesia. Environmental Health Perspectives, 87, 199-205. https://doi.org/10.1289/ehp.9087199

[16] Forman, S.A. and Chin, V.A. (2008) General Anesthetics and Molecular Mechanisms of Unconsciousness. International Anesthesiology Clinics, 46, 43-53. https://doi.org/10.1097/AIA.0b013e3181755da5

[17] Forman, S.A. and Miller, K.W. (2011) Anesthetic Sites and Allosteric Mechanisms of Action on Cys-Loop Ligand-Gated Ion Channels. Canadian Journal of Anesthesia, 58, 191-205. https://doi.org/10.1007/s12630-010-9419-9

[18] Heusser, S.A., et al. (2018) Allosteric Potentiation of a Ligand-Gated Ion Channel Is Mediated by Access to a Deep Membrane-Facing Cavity. Proceedings of the National Academy of Sciences of the United States of America, 115, 10672-10677. https://doi.org/10.1073/pnas.1809650115 
[19] Fourati, Z., et al. (2018) Structural Basis for a Bimodal Allosteric Mechanism of General Anesthetic Modulation in Pentameric Ligand-Gated Ion Channels. Cell Rep, 23, 993-1004. https://doi.org/10.1016/j.celrep.2018.03.108

[20] Zhou, C., Liu, J. and Chen, X.D. (2012) General Anesthesia Mediated by Effects on Ion Channels. World Journal of Critical Care Medicine, 1, 80-93. https://doi.org/10.5492/wjccm.v1.i3.80

[21] Dilger, J.P. (2002) The Effects of General Anaesthetics on Ligand-Gated Ion Channels. British Journal of Anaesthesia, 89, 41-51. https://doi.org/10.1093/bja/aef161

[22] Herd, M.B., Brown, A.R., Lambert, J.J. and Belelli, D. (2013) Extrasynaptic GABA Receptors Couple Presynaptic Activity to Postsynaptic Inhibition in the Somatosensory Thalamus. Journal of Neuroscience, 33, 14850-14868. https://doi.org/10.1523/JNEUROSCI.1174-13.2013

[23] Herd, M.B., Lambert, J.J. and Belelli, D. (2014) The General Anaesthetic Etomidate Inhibits the Excitability of Mouse Thalamocortical Relay Neurons by Modulating Multiple Modes of GABAA Receptor-Mediated Inhibition. European Journal of Neuroscience, 40, 2487-2501. https://doi.org/10.1111/ejn.12601

[24] Belelli, D., Pistis, M., Peters, J.A. and Lambert, J.J. (1999) General Anaesthetic Action at Transmitter-Gated Inhibitory Amino Acid Receptors. Trends in Pharmacological Sciences, 20, 496-502. https://doi.org/10.1016/S0165-6147(99)01405-4

[25] Rudolph, U. and Antkowiak, B. (2004) Molecular and Neuronal Substrates for General Anaesthetics. Nature Reviews Neuroscience, 5, 709-720. https://doi.org/10.1038/nrn1496

[26] Cayla, N.S., et al. (2019) A Newly Developed Anesthetic Based on a Unique Chemical Core. Proceedings of the National Academy of Sciences of the United States of America, 116, 15706-15715. https://doi.org/10.1073/pnas.1822076116

[27] Jurd, R., et al. (2003) General Anesthetic Actions in Vivo Strongly Attenuated by a Point Mutation in the $\mathrm{GABA}_{\mathrm{A}}$ Receptor beta3 Subunit. The FASEB Journal, 17, 250-252. https://doi.org/10.1096/fj.02-0611fje

[28] Spurny, R., et al. (2012) Pentameric Ligand-Gated Ion Channel ELIC Is Activated by GABA and Modulated by Benzodiazepines. Proceedings of the National Academy of Sciences of the United States of America, 109, E3028-E3034. https://doi.org/10.1073/pnas.1208208109

[29] Bertaccini, E.J., Wallner, B., Trudell, J.R. and Lindahl, E. (2010) Modeling Anesthetic Binding Sites within the Glycine Alpha One Receptor Based on Prokaryotic Ion Channel Templates: The Problem with TM4. Journal of Chemical Information and Modeling, 50, 2248-2255. https://doi.org/10.1021/ci100266c

[30] Bertaccini, E.J., Yoluk, O., Lindahl, E.R. and Trudell, J.R. (2013) Assessment of Homology Templates and an Anesthetic Binding Site within the Gamma-Aminobutyric Acid Receptor. Anesthesiology, 119, 1087-1095. https://doi.org/10.1097/ALN.0b013e31829e47e3

[31] Krasowski, M.D. and Harrison, N.L. (1999) General Anaesthetic Actions on Ligand-Gated Ion Channels. Cellular and Molecular Life Sciences, 55, 1278-1303. https://doi.org/10.1007/s000180050371

[32] Hill-Venning, C., Belelli, D., Peters, J.A. and Lambert, J.J. (1997) Subunit-Dependent Interaction of the General Anaesthetic Etomidate with the Gamma-Aminobutyric Acid Type A Receptor. British Journal of Pharmacology, 120, 749-756. https://doi.org/10.1038/sj.bjp.0700927

[33] Belelli, D., Lambert, J.J., Peters, J.A., Wafford, K. and Whiting, P.J. (1997) The Inte- 
raction of the General Anesthetic Etomidate with the Gamma-Aminobutyric Acid Type a Receptor Is Influenced by a Single Amino Acid. Proceedings of the National Academy of Sciences of the United States of America, 94, 11031-11036. https://doi.org/10.1073/pnas.94.20.11031

[34] Fahrenbach, V.S. and Bertaccini, E.J. (2018) Insights into Receptor-Based Anesthetic Pharmacophores and Anesthetic-Protein Interactions. Methods in Enzymology, 602, 77-95. https://doi.org/10.1016/bs.mie.2018.01.004

[35] Forman, S.A. (2011) Clinical and Molecular Pharmacology of Etomidate. Anesthesiology, 114, 695-707. https://doi.org/10.1097/ALN.0b013e3181ff72b5

[36] Wagner, R.L., White, P.F., Kan, P.B., Rosenthal, M.H. and Feldman, D. (1984) Inhibition of Adrenal Steroidogenesis by the Anesthetic Etomidate. The New England Journal of Medicine, 310, 1415-1421. https://doi.org/10.1056/NEJM198405313102202

[37] Asproni, B., et al. (2005) Synthesis, Structure-Activity Relationships at the $\mathrm{GABA}_{\mathrm{A}}$ Receptor in Rat Brain, and Differential Electrophysiological Profile at the Recombinant Human GABA(A) Receptor of a Series of Substituted 1,2-Diphenylimidazoles. Journal of Medicinal Chemistry, 48, 2638-2645. https://doi.org/10.1021/jm049120y

[38] Cotten, J.F., et al. (2010) Carboetomidate: A Pyrrole Analog of Etomidate Designed Not to Suppress Adrenocortical Function. Anesthesiology, 112, 637-644. https://doi.org/10.1097/ALN.0b013e3181cf40ed

[39] Mascia, M.P., et al. (2005) Ethyl 2-(4-bromophenyl)-1-(2,4-dichlorophenyl)-1H-4imidazolecarboxylate Is a Novel Positive Modulator of GABAA Receptors. European Journal of Pharmacology, 516, 204-211. https://doi.org/10.1016/j.ejphar.2005.05.006

[40] Shanmugasundararaj, S., et al. (2013) Carboetomidate: An Analog of Etomidate That Interacts Weakly with 11beta-Hydroxylase. Anesthesia \& Analgesia, 116, 1249-1256. https://doi.org/10.1213/ANE.0b013e31828b3637

[41] Bieda, M.C., Su, H. and Maciver, M.B. (2009) Anesthetics Discriminate between Tonic and Phasic Gamma-Aminobutyric Acid Receptors on Hippocampal CA1 Neurons. Anesthesia \& Analgesia, 108, 484-490. https://doi.org/10.1213/ane.0b013e3181904571

[42] MacIver, M.B. (2014) Anesthetic Agent-Specific Effects on Synaptic Inhibition. Anesthesia \& Analgesia, 119, 558-569. https://doi.org/10.1213/ANE.0000000000000321

[43] Downes, H. and Courogen, P.M. (1996) Contrasting Effects of Anesthetics in Tadpole Bioassays. Journal of Pharmacology and Experimental Therapeutics, 278, 284-296.

[44] Smith, W. (1993) Responses of Laboratory Animals to Some Injectable Anaesthetics. Laboratory Animals, 27, 30-39. https://doi.org/10.1258/002367793781082377

[45] Wang, B., et al. (2017) An Etomidate Analogue with Less Adrenocortical Suppression, Stable Hemodynamics, and Improved Behavioral Recovery in Rats. Anesthesia \& Analgesia, 125, 442-450. https://doi.org/10.1213/ANE.0000000000002063 